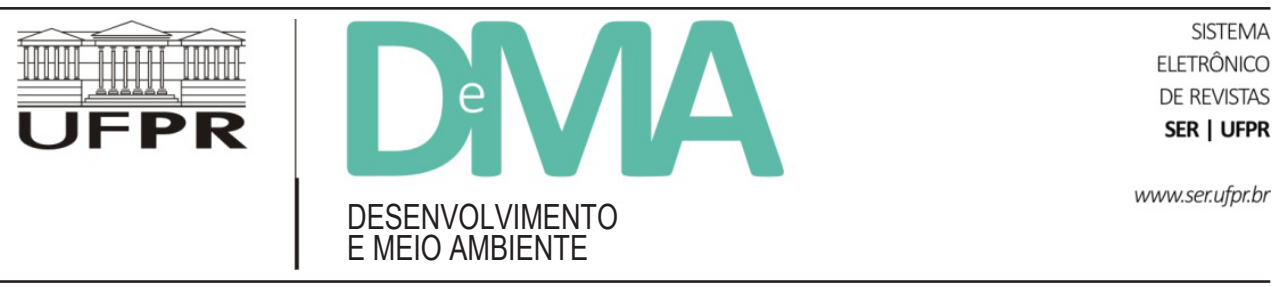

\title{
Recursos da geodiversidade de São Thomé das Letras - MG e seu uso para mineração e geoconservação: perspectivas para a reconversão desse território mineiro
}

\section{São Thomé das Letras - MG Geodiversity Resources and its Use for Mining and Geoconservation: Territory Reconversion}

\author{
Camila LOPES ${ }^{1 *}$, Úrsula RUCHKYS ${ }^{1}$ \\ ${ }^{1}$ Instituto de Geociências, Departamento de Cartografia, Universidade Federal de Minas Gerais (UFMG), Belo Horizonte, MG, Brasil. \\ ${ }^{*}$ E-mail de contato: ief.camila@gmail.com
}

Artigo recebido em 28 de abril de 2015, versão final aceita em 4 de dezembro de 2015.

RESUMO: Territórios mineradores convivem com conflitos de interesse envolvendo a conservação do patrimônio e a exploração mineral. A perspectiva de usos alternativos para essas áreas vem sendo frequentemente mencionada no contexto do desenvolvimento regional, sendo denominada de reconversão. Este artigo tem como objetivo propor cenários territoriais que priorizem a integração da atividade minerária, com foco naquelas paralisadas, abandonadas ou em processo de fechamento, com medidas de conservação do patrimônio geológico e mineiro do município de São Thomé das Letras, Minas Gerais. O método empregado envolveu a modelagem dinâmica espacial vinculada às geotecnologias e análise multicritério para construção de um cenário integrado, considerando tanto o uso para extração mineral como para geoconservação. Espera-se que este resultado possa subsidiar o ordenamento territorial do município e auxiliar na reconversão desse território ao apontar seus valores histórico, turístico, didático e educativo ligados à geodiversidade e às minas abandonadas, paralisadas ou em processo de fechamento que integram a história da mineração na região.

Palavras-chave: modelagem de cenários; geotecnologias; geoconservação; reconversão de territórios.

ABSTRACT: Mining territories live with interest conflict involving heritage conservation and mineral exploration. The prospect of alternative uses for these areas has frequently been mentioned in the context of regional development, and called for the conversion. This article aims at proposing territorial scenarios that focus on the integration of mining activity, focusing on those paralyzed, abandoned or closing processes, with conservation measures of geological and mining heritage of São Thomé das Letras, Minas Gerais. The method involved spatial dynamic modelling linked to geotechnology and Multicriteria Analysis for building an integrated scenario considering both the use for mining and for geoconservation. It is expected that this result may support the territorial planning of the municipality and assist in the conversion of that territory by pointing out its historical, tourist, didactic and educational values linked to geodiversity and abandoned mines, paralyzed or closing processes that integrate the history of mining in the region.

Keywords: scenario modelling; geotechnology; geoconservation; territories conversion. 


\section{Introdução}

Assim como a biodiversidade corresponde à diversidade da natureza viva, mais recentemente, a partir da década de 1990, começou a se utilizar o termo geodiversidade para designar a variedade de estruturas (sedimentares, tectônicas, geomorfológicas e petrológicas) e materiais geológicos (minerais, rochas, fósseis e solos) que constituem o substrato físico natural de uma região e que suportam a biodiversidade.

Em 2001, Nieto amplia a definição do termo, incluindo o aspecto humano:

A geodiversidade consiste no número e variedade de estruturas (sedimentares, tectônicas, geomorfológicas, hidrogeológicas e petrológicas) e de materiais geológicos (minerais, rochas, fósseis e solos), que constituem o substrato físico e natural de uma região, sobre o qual se assenta a atividade orgânica, incluindo-se a antrópica (Nieto, 2001, p. 7).

A geodiversidade pode apresentar diferentes valores, conforme elencado por Gray (2004): valor intrínseco ou de existência, valores culturais (influência sobre folclore, arquitetura, história e religião), estéticos (oportunidade de lazer, contemplação, inspiração para a arte), econômicos (recursos minerais e energéticos), funcionais (sobretudo como substrato para os ecossistemas), científicos e educacionais.

Tantos valores associados à geodiversidade podem gerar conflitos e interesses contraditórios, principalmente onde o valor econômico está presente, o que implica, na grande maioria das vezes, em atividades de extração mineral. A mineração é considerada uma das bases da economia do Brasil, sendo um setor estratégico para dinamizar o crescimento econômico de muitos municípios. Se por um lado a necessidade econômica implica na valorização da mineração, por outro essa atividade pode gerar uma grande quantidade de resíduos que, descartados no meio ambiente de forma não cuidadosa, causam impactos.

Os laços entre o homem e a geodiversidade são muitas vezes fortalecidos por questões econômicas, quando as comunidades são dependentes dos georrecursos dos quais sua vida depende. Além disto, os elementos da geodiversidade têm um elevado potencial educativo, cultural e recreativo, relacionando-se assim ao conceito de patrimônio, o que justifica a necessidade de medidas de conservação e valorização (Ruchkys, 2015). Estas medidas, quando associadas aos elementos da geodiversidade, recebem a denominação de geoconservação, que integra ações que vão desde a proteção física de afloramentos rochosos até a interpretação do patrimônio geológico e mineiro para uso pelo turismo.

Gallego \& García (1996) definem o patrimônio geológico como o conjunto de recursos naturais não renováveis de valor científico, cultural e educativo, incluindo as formações, estruturas geológicas, formas do terreno, os jazimentos paleontológicos e mineralógicos, que permitem reconhecer, estudar e interpretar a evolução da história geológica da Terra e os processos que têm modelado.

Ruchkys \& Machado (2013) salientam a estreita relação existente entre o patrimônio geológico e o mineiro, uma vez que as atividades minerárias se desenvolvem de forma condicionada às características geológicas. Cañizares (2005) define o patrimônio mineiro como a herança da mineração e de origem industrial, incluindo bens materiais e o legado intangível desenvolvidos no passado ou no presente e que fazem parte da identidade cultural de grupos sociais em determinados momentos de sua história. Assim, o patrimônio mineiro inclui tanto os valores tangíveis como os intangíveis relacionados à prática da mineração e está associado tanto a atividades extrativas antigas como atuais.

Buscando contribuir para o planejamento e para o ordenamento de territórios onde o conflito pelo uso dos recursos naturais se faz presente, têm sido desenvolvidas várias metodologias e ferramentas, com destaque para o geoprocessamento, que inclui os Sistemas de Informações Geográficas (SIGs) e o sensoriamento remoto. Dentre os métodos empregados, pode-se citar a análise multicritério utilizada para integrar diferentes variáveis na análise de uma situação complexa.

A partir dessas considerações, o artigo tem como objetivo apresentar um cenário territorial para o município de São Thomé das Letras que represente duas visões de desenvolvimento para a área de forma integrada: exploração mineral e geoconservação. Com isso, pretende-se contribuir para a discussão sobre a 
reconversão de territórios mineradores ao pensar seu uso após o fechamento de minas e seu potencial como patrimônio geológico e mineiro, podendo integrar planos de desenvolvimento regional - agregando valor a produtos turísticos tradicionais já existentes - e contribuir para a reconversão desta importante região mineradora.

\section{São Thomé das Letras: mineração e patrimônio}

São Thomé das Letras pertence à Microrregião de Varginha, compreendida na Mesorregião Sul/Sudoeste de Minas Gerais, integrante da área produtora de quartzito ornamental, localmente conhecido como pedra São Tomé, que engloba os seguintes municípios: São Thomé das Letras, Três Corações, São Bento Abade, Carrancas,
Minduri, Cruzília, Caxambu, Conceição do Rio Verde e Varginha (Figura 1).

O município faz parte do Circuito Turístico Vale Verde e Quedas D’Água e está situado em uma área cuja paisagem vem sendo modificada desde o século XVIII devido às ações antrópicas relacionadas à exploração dos quartzitos.

D’Auria (2000), por meio de uma pesquisa histórica, caracteriza cinco fases na exploração do quartzito na região: a primeira envolve a retirada dos primeiros fragmentos de rocha utilizados pelos colonizadores e dura até o final do século XIX; o período do final do século XIX até o início da década de 1940 é denominado de "indústria da pedra", quando começam a ser explorados os quartzitos do alto da serra; entre 1940 e 1970 foram incorporados explosivos nos processos de lavra; de 1970 a 1990 tem início uma série de denúncias sobre

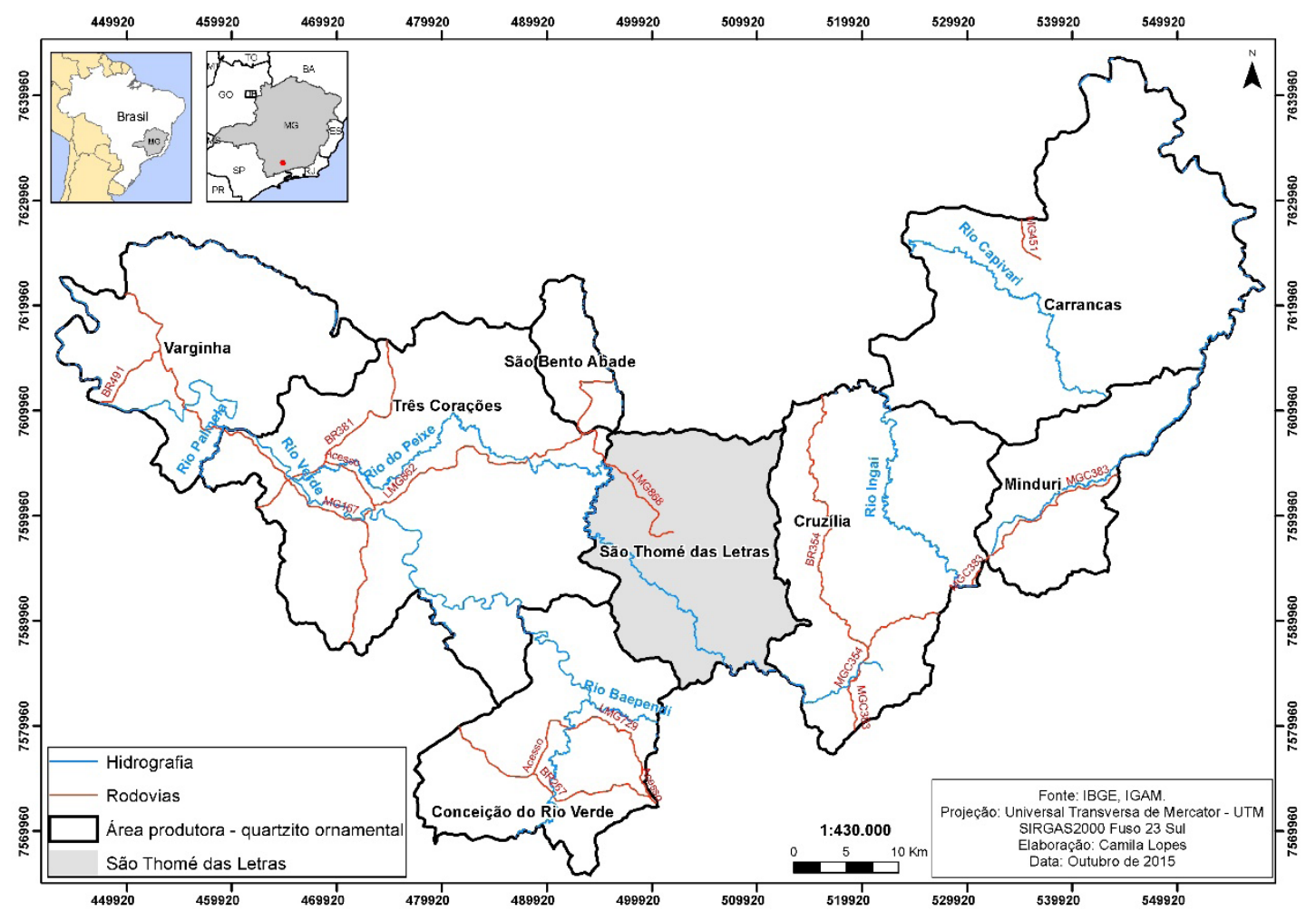

FIGURA 1 - Mapa de localização dos municípios produtores de pedra São Tomé, com destaque para o município de São Thomé das Letras. 
a extração e o poder público começa a atuar; a última fase é caracterizada pela incorporação de medidas que visam satisfazer as exigências legais relacionadas principalmente aos processos de licenciamento ambiental. Rezende et al. (2009) destacam que na atualidade a extração é feita em duas etapas, a primeira com a utilização de máquinas e a segunda de maneira artesanal, quando movimentos do corpo e ferramentas rudimentares são utilizados no desplacamento das lajes. Fernandes et al. (2002) colocam que a rocha é exportada para países da Europa e para o Japão desde a década de 1990.

Mesmo trazendo degradação ambiental, a exploração histórica desse recurso da geodiversidade caracteriza o patrimônio construído, tombado pelo Instituto Estadual do Patrimônio Histórico e Artístico (IEPHA). Segundo D'Auria (2000), explorados desde as últimas décadas dos setecentos, os quartzitos presentes na Serra das Letras constituíram a matéria-prima privilegiada para construção de igrejas e casarios, cujas rochas foram cuidadosamente cortadas e empilhadas uma a uma, sem qualquer tipo de argamassa, o que emprestou a ela o apelido de "Cidade de Pedra".

Carvalho \& Pereira (2010) mostram a importância da pedra São Tomé para a atividade de artesanato, que se configura como uma alternativa de fonte de renda para a população. Para esse tipo de produção são utilizadas peças pequenas, muitas vezes oriundas do monte de resíduo das mineradoras. Os produtos mais encontrados são: casa de pedra, abajur, disco voador, porta-incenso, bijuteria, semijoia, porta-retratos e moldura de espelho.

A abundância, a dimensão e a densidade de ocorrência dos quartzitos na Serra das Letras encerram um rico patrimônio natural associado a afloramentos rochosos e cavernas. Travassos et al. (2008) destacam a importância de várias cavernas envoltas por lendas e histórias fantásticas, incluindo: a Gruta de São Tomé, que tem seu nome creditado a uma lenda que reza que um escravo fugido teria recebido uma carta de um homem que afirmava ser São Tomé; Grutas do Carimbado I e II, com 33 m e 212 m, respectivamente, que no imaginário popular são ligadas à cidade de Machu Pichu, no Peru; Gruta do Índio; Gruta das Bruxas; Gruta do Labirinto, com 226 m, e a Gruta Sobradinho (MG-1682), com 150 $\mathrm{m}$, todas em quartzito. Conforme afirmam Rezende et al. (2009), algumas cavidades abrigam importantes sítios ar- queológicos com pinturas rupestres já reconhecidos pelo Instituto do Patrimônio Histórico e Artístico Nacional (IPHAN), sendo três na zona urbana, sete em áreas de mineração, duas na Área de Proteção Ambiental (APA) de São Tomé das Letras, uma na zona rural e uma no Pico do Peão, afastada de área de mineração. Estes exemplos configuram o valor cultural associado à geodiversidade.

Além das cavernas, o município é caracterizado por vários atrativos ligados ao patrimônio geológico, incluindo cachoeiras, nascentes, canyons e trilhas naturais. Do ponto de vista biótico, Lopes et al. (2013) afirmam que a cobertura vegetal da região de São Thomé das Letras constitui-se de uma área de transição entre as florestas semidecíduas do sudeste e sul do país e o cerrado do Brasil central, incluindo aí o cerrado rupestre, o campo sujo, o campo limpo e o campo rupestre.

Os recursos da geodiversidade presentes no município são a base para o desenvolvimento de suas duas principais atividades econômicas: o turismo e a mineração. No entanto, como salienta Santos (2005), a atividade minerária ainda é realizada de forma não sistematizada, gera pilhas de rejeitos, trazendo riscos para o patrimônio. A extensiva ocorrência de quartzito e todo o valor a ele associado torna esta região fascinante, sendo necessária não só a exploração de forma mais sustentável, mas também medidas que levem à sua conservação.

Cañizares (2011a) salienta que em áreas de mineração o patrimônio também pode se converter em um objeto de memória coletiva, expressão cultural com valores simbólicos, artísticos, históricos e funcionais, o que pode implicar na valorização pela própria comunidade local de seus recursos materiais (edificações) e, sobretudo, imateriais (cultura mineira) vinculados com as minas e com espaços musealizados. Para ações desta natureza, tem sido utilizado o termo reconversão.

\section{Reconversão de territórios mineradores}

Cañizares (2011a e 2011b) destaca que áreas de intensa atividade mineradora podem estar associadas à presença de importante patrimônio natural e cultural e suas paisagens podem ser reabilitadas e recuperadas para uso turístico, sendo esta uma das melhores estratégias para preservar e valorizar o patrimônio mineiro. 
Para Cañizares (2011b), a reconversão de territórios com rico legado cultural deixado pela mineração tem sido a base de várias ações voltadas para a melhoria desses territórios, envolvendo principalmente o turismo. O patrimônio mineiro aparece então como uma nova oportunidade de desenvolvimento, ao transformar estas regiões em destinos turísticos.

No Brasil, aconteceu em 2012 o I Seminário Internacional de Reconversão de Territórios, organizado pela Fundação Estadual de Meio Ambiente de Minas Gerais (FEAM), onde o termo reconversão foi utilizado para se referir à qualidade ambiental e socioeconômica de antigos territórios minerários e industriais. Estudos de reconversão de territórios mineradores abordam, além da reabilitação dos aspectos físicos, os seguintes aspectos: a reconstrução da identidade local em face de alterações culturais e territoriais advindas da mineração; a análise dos impactos socioeconômicos decorrentes do fechamento das atividades industriais e minerárias; a análise de indicadores socioeconômicos e urbanos; e a indicação de instrumentos de ordenamento territorial para sua recuperação.

Para Saiz de Omeñaca \& Saiz de Omeñaca (1996), ao se pensar na reconversão, além da reabilitação é importante pensar o uso futuro da área, sendo o turismo ligado ao legado do patrimônio mineiro uma das perspectivas mais interessantes, já que valoriza a identidade cultural das comunidades.

Essa concepção entende que a construção de parcerias entre comunidade, governo e entidades privadas possibilitará o melhor aproveitamento desse tipo de região em termos de uso turístico, qualidade de vida e lazer, trazendo novas oportunidades para o desenvolvimento regional e econômico, com novas possibilidades de negócios (Accioly, 2012). Assim, trabalhos de reconversão têm criado alternativas de emprego e recuperação econômica de antigos territórios minerários e industriais.

Segundo Accioly (2012), podem ser citadas propostas que incluem o resgate da memória minerária e industrial, como é o caso de Lusatia (Alemanha), onde estava instalada uma mineração de linhito. A transformação da paisagem incluiu o reconhecimento de um patrimônio industrial, incentivando a preservação e a reutilização de exemplos da história industrial da região, testemunho da sua historicidade, valorizando a identidade cultural. Foi feita a abertura de áreas ainda em operação para visitas ao público em geral, especialmente para estudantes e pesquisadores interessados no processo produtivo.

Outro exemplo é o caso do Geoparque Arouca, em Portugal, onde existia uma mineração de ardósia, utilizada para revestimento. Neste ambiente, e em continuidade com a lavra, foi encontrado e preservado um sítio paleontológico com ocorrência de exemplares excepcionais de trilobitas paleozoicos gigantes (Gutiérrez-Marco et al., 2009).

A mineração e a geoconservação são, em princípio, excludentes, uma vez que a primeira é necessariamente modificadora do meio original, enquanto que a segunda é conservacionista, em geral. Apesar de serem ainda incipientes os exemplos brasileiros que conciliem essas atividades, pode-se citar o trabalho de Gesicki \& Santucci (2011), no qual os autores apresentam um estudo de caso envolvendo a proteção de um sítio paleontológico em uma área de mineração ativa de calcário em Santa Rosa de Viterbo, interior do Estado de São Paulo. O objetivo deste trabalho foi demonstrar ser viável a implantação de medidas de geoconservação em áreas onde a mineração está em plena atividade.

Outro exemplo bem sucedido de reconversão de territórios mineradores é o caso de Curitiba, que reabilitou três antigas áreas de mineração e criou parques para a cidade: o Parque das Pedreiras, o bosque Zaninelli e o Parque Tanguá. Antigamente funcionavam nessas áreas: pedreiras, usina de asfalto, exploração de granito e que, após o encerramento das atividades, se tornaram abandonadas e alvo de depósito de lixo. Atualmente, elas se tornaram espaços de cultura e lazer, ambientalmente preservados (Liccardo et al., 2008).

Todos esses exemplos mantiveram estruturas e resquícios do passado minerário e industrial, sendo esses registros integrantes da identidade local.

\section{Métodos da pesquisa}

Os métodos de pesquisa envolveram as seguintes etapas: levantamento bibliográfico; pesquisa de campo; seleção das variáveis a serem analisadas e consultas com especialistas; aplicação de análise multicritério e 
álgebra de mapas para elaboração dos cenários de mineração e de geoconservação; e avaliação das matrizes de interesse para construção do cenário integrado. Nos dois cenários, a seleção das variáveis foi baseada na sua importância para exploração mineral e para práticas de geoconservação.

Para o cenário favorável à geoconservação, foram utilizadas as seguintes variáveis: atrativos turísticos, áreas de exploração mineral inativas; estradas e vias de acesso; unidades de conservação de proteção integral e de uso sustentável; afloramento rochoso; áreas de preservação permanente; índice de geodiversidade. Antes da aplicação da análise multicritério, foram definidas áreas de influência no entorno dos elementos listados a seguir, considerando o critério de proximidade: atrativos turísticos; áreas de exploração mineral inativas; estradas e vias de acesso; unidades de conservação de proteção integral e de uso sustentável; afloramento rochoso. O índice de geodiversidade foi feito a partir do método desenvolvido por Serrano \& Ruiz-Flaño (2007), Hjort \& Luoto (2010), Pellitero (2012) e Pereira et al. (2013).

Para o cenário favorável à exploração mineral, foram utilizadas as seguintes variáveis: quartzito; vias de acesso; processos minerários no Departamento Nacional de Pesquisa Mineral (DNPM); ocorrência de recurso mineral; minas ativas. Para todas essas variáveis utilizadas foram definidas áreas de influência considerando o critério de proximidade.

A ponderação das variáveis nos dois cenários se pautou na metodologia DELPHI, de consulta a especialistas. Para o cenário de geoconservação, foram consultados profissionais que desenvolvem pesquisas e que têm publicações envolvendo geodiversidade, geoconservação e patrimônio geológico. Para o cenário de exploração mineral, optou-se pela consulta a profissionais da Fundação Estadual de Meio Ambiente (FEAM) que atuam na região de São Thomé das Letras em processos relacionados a questões ambientais legais da exploração mineral do quartzito. Para os dois cenários, foi aplicada análise multicritério e a álgebra adotada foi de lógica fuzzy.

A última etapa foi a elaboração do cenário integrado. As variáveis de entrada do modelo foram os mapas de aptidão resultantes da modelagem do cenário favorável à exploração mineral e do cenário favorável à geoconservação. Optou-se por usar o mesmo peso para cada cenário, buscando não priorizar a identificação das áreas mais aptas para a mineração e nem para a geoconservação. Desta forma, tanto o cenário de mineração quanto o cenário de geoconservação receberam peso 0.5 na modelagem final. Os resultados destes dois cenários foram combinados, gerando 25 possíveis resultados, considerando que cada um dos cenários apresentou cinco componentes de legenda, de muito baixo a muito alto interesse.

\section{Resultados e discussões}

\subsection{Cenários favoráveis à geoconservação e à exploração mineral}

A determinação dos valores de notas e pesos para cada uma das variáveis utilizadas, como já explicado, foi baseada em opinião de especialistas utilizando o método DELPHI. No caso do cenário favorável à geoconservação, estes dados estão apresentados na Tabela 1 e, no do cenário favorável à exploração mineral, na Tabela 2 .

As notas variaram de 0 a 5 e foram estabelecidas considerando o grau de proximidade, ou seja, quanto menor a distância da variável utilizada, maior a nota atribuída.

A partir da análise do mapa (Figura 2), é possível observar que o município apresenta vários pontos de alta aptidão para geoconservação, principalmente associados às nascentes e às áreas de altas altitudes e declividades. Esses pontos estão distribuídos na linha de cumeada das duas serras, tendendo a diminuir em quantidade à medida que a declividade diminui. No mapa resultante, é possível observar que as áreas de maior aptidão à geoconservação estão associadas à presença de atrativos turísticos, que, por sua vez, também apresentam forte relação com a presença do quartzito, já que os locais mais procurados por visitantes são grutas e cachoeiras. Também foram classificadas como áreas de maior aptidão, para este propósito, aquelas próximas às Unidades de Conservação (UCs) e às Áreas de Preservação Permanentes (APPs) de topo de morro, onde ocorrem locais que estão ligados à geodiversidade de São Thomé das Letras, principalmente 
TABELA 1 - Pesos e notas para o cenário favorável à geoconservação.

\begin{tabular}{|c|c|c|c|}
\hline Variável & Peso & $\begin{array}{l}\text { Componente de } \\
\text { legenda }\end{array}$ & Nota \\
\hline \multirow{6}{*}{$\begin{array}{c}\text { Proximidade de atrativos } \\
\text { turísticos }\end{array}$} & \multirow{6}{*}{$25 \%$} & $0-2 \mathrm{~km}$ & 5 \\
\hline & & $2-4 \mathrm{~km}$ & 4 \\
\hline & & $4-6 \mathrm{~km}$ & 3 \\
\hline & & $6-8 \mathrm{~km}$ & 2 \\
\hline & & $8-10 \mathrm{~km}$ & 1 \\
\hline & & $>10 \mathrm{~km}$ & 0 \\
\hline \multirow{6}{*}{$\begin{array}{l}\text { Proximidade de Áreas de } \\
\text { Exploração Mineral Inativa }\end{array}$} & \multirow{6}{*}{$20 \%$} & $0-2 \mathrm{~km}$ & 5 \\
\hline & & $2-4 \mathrm{~km}$ & 4 \\
\hline & & $4-6 \mathrm{~km}$ & 3 \\
\hline & & $6-8 \mathrm{~km}$ & 2 \\
\hline & & $8-10 \mathrm{~km}$ & 1 \\
\hline & & $>10 \mathrm{~km}$ & 0 \\
\hline \multirow{6}{*}{$\begin{array}{c}\text { Proximidade de estradas e } \\
\text { vias de acesso }\end{array}$} & \multirow{6}{*}{$20 \%$} & $0-1 \mathrm{~km}$ & 5 \\
\hline & & $1-2 \mathrm{~km}$ & 4 \\
\hline & & $2-3 \mathrm{~km}$ & 3 \\
\hline & & $3-4 \mathrm{~km}$ & 2 \\
\hline & & $4-5 \mathrm{~km}$ & 1 \\
\hline & & $>5 \mathrm{~km}$ & 0 \\
\hline \multirow{6}{*}{$\begin{array}{l}\text { Proximidade de Unidades } \\
\text { de Conservação - Proteção } \\
\text { Integral e Uso Sustentável }\end{array}$} & \multirow{6}{*}{$10 \%$} & $0-1 \mathrm{~km}$ & 5 \\
\hline & & $1-2 \mathrm{~km}$ & 4 \\
\hline & & $2-3 \mathrm{~km}$ & 3 \\
\hline & & $3-4 \mathrm{~km}$ & 2 \\
\hline & & $4-5 \mathrm{~km}$ & 1 \\
\hline & & $>5 \mathrm{~km}$ & 0 \\
\hline \multirow{6}{*}{$\begin{array}{l}\text { Proximidade de } \\
\text { Afloramento Rochoso }\end{array}$} & \multirow{6}{*}{$10 \%$} & $0-2 \mathrm{~km}$ & 5 \\
\hline & & $2-4 \mathrm{~km}$ & 4 \\
\hline & & $4-6 \mathrm{~km}$ & 3 \\
\hline & & $6-8 \mathrm{~km}$ & 2 \\
\hline & & $8-10 \mathrm{~km}$ & 1 \\
\hline & & $>10 \mathrm{~km}$ & 0 \\
\hline $\begin{array}{c}\text { Áreas de Preservação } \\
\text { Permanente }\end{array}$ & $10 \%$ & Presença & 5 \\
\hline $\begin{array}{l}\text { Alto Índice de } \\
\text { Geodiversidade }\end{array}$ & $5 \%$ & Presença & 5 \\
\hline
\end{tabular}

TABELA 2 - Pesos e notas para o cenário favorável à exploração mineral.

\begin{tabular}{|c|c|c|c|}
\hline Variável & Peso & $\begin{array}{l}\text { Componente de } \\
\text { legenda }\end{array}$ & Nota \\
\hline Quartzito & $50 \%$ & Presença & 5 \\
\hline \multirow{6}{*}{$\begin{array}{l}\text { Proximidade de vias de } \\
\text { acesso }\end{array}$} & \multirow{6}{*}{$20 \%$} & $0-1 \mathrm{~km}$ & 5 \\
\hline & & $1-2 \mathrm{~km}$ & 4 \\
\hline & & $2-3 \mathrm{~km}$ & 3 \\
\hline & & $3-4 \mathrm{~km}$ & 2 \\
\hline & & $4-5 \mathrm{~km}$ & 1 \\
\hline & & $>5 \mathrm{~km}$ & 0 \\
\hline \multirow{6}{*}{$\begin{array}{l}\text { Proximidade de processos } \\
\text { minerários do DNPM }\end{array}$} & \multirow{6}{*}{$10 \%$} & $0-1 \mathrm{~km}$ & 5 \\
\hline & & $1-2 \mathrm{~km}$ & 4 \\
\hline & & $2-3 \mathrm{~km}$ & 3 \\
\hline & & $3-4 \mathrm{~km}$ & 2 \\
\hline & & $4-5 \mathrm{~km}$ & 1 \\
\hline & & $>5 \mathrm{~km}$ & 0 \\
\hline \multirow{6}{*}{$\begin{array}{l}\text { Proximidade de ocorrência } \\
\text { de recurso mineral }\end{array}$} & \multirow{6}{*}{$10 \%$} & $0-1 \mathrm{~km}$ & 5 \\
\hline & & $1-2 \mathrm{~km}$ & 4 \\
\hline & & $2-3 \mathrm{~km}$ & 3 \\
\hline & & $3-4 \mathrm{~km}$ & 2 \\
\hline & & $4-5 \mathrm{~km}$ & 1 \\
\hline & & $>5 \mathrm{~km}$ & 0 \\
\hline \multirow{6}{*}{ Proximidade de minas } & \multirow{6}{*}{$10 \%$} & $0-1 \mathrm{~km}$ & 5 \\
\hline & & $1-2 \mathrm{~km}$ & 4 \\
\hline & & $2-3 \mathrm{~km}$ & 3 \\
\hline & & $3-4 \mathrm{~km}$ & 2 \\
\hline & & $4-5 \mathrm{~km}$ & 1 \\
\hline & & $>5 \mathrm{~km}$ & 0 \\
\hline
\end{tabular}

em relação às rochas e ao relevo. Nas áreas classificadas como de alta aptidão para geoconservação, estão famosos atrativos turísticos do município, com destaque para a Gruta de São Thomé (Figura 3), a Pedra da Bruxa (Figura 4) e a Pirâmide (Figura 5). 


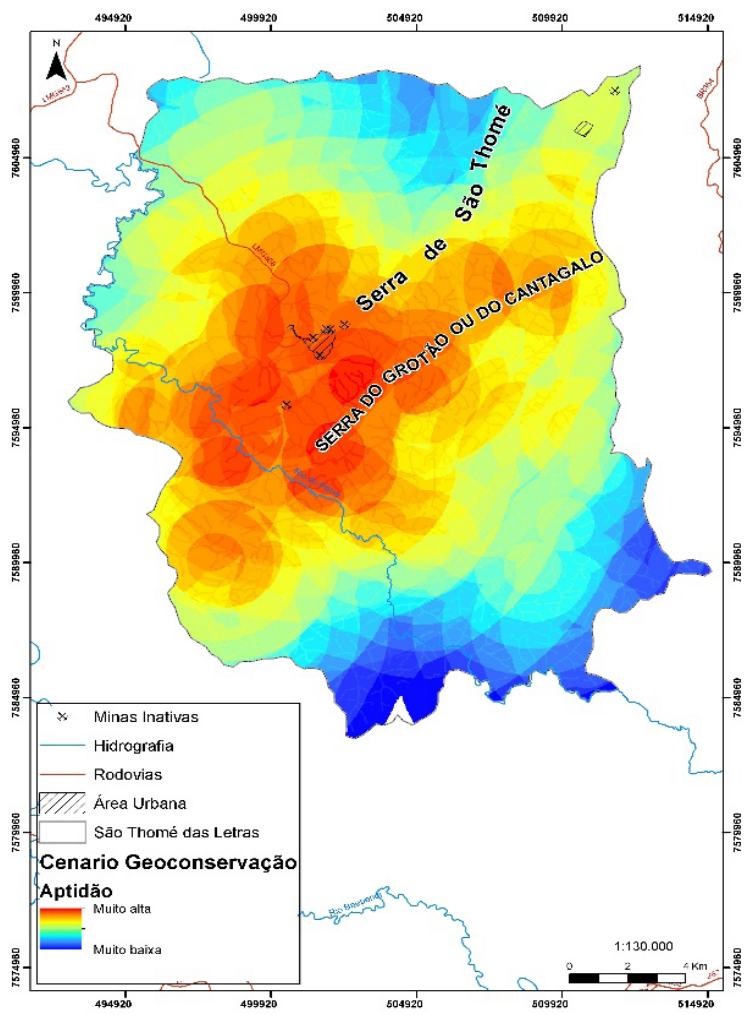

FIGURA 2 - Mapa do cenário de favorável à geoconservação.

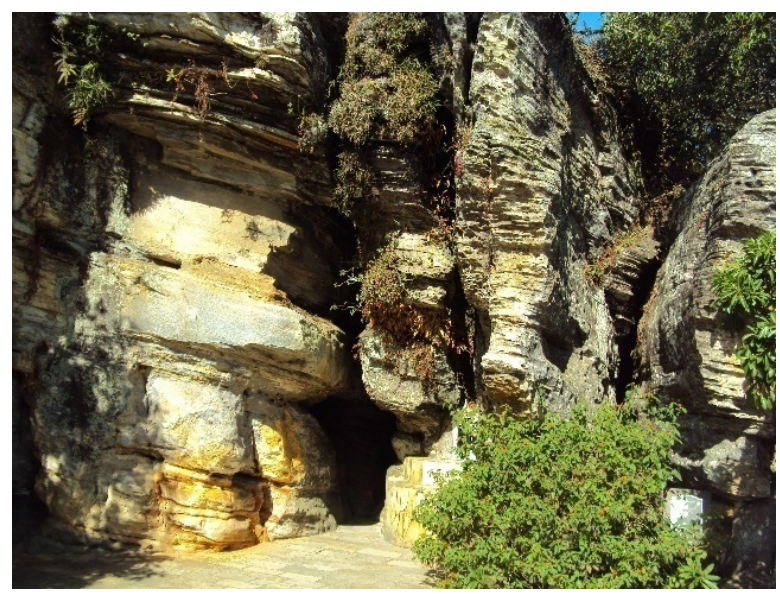

FIGURA 3 - Atrativo turístico Gruta de São Thomé.

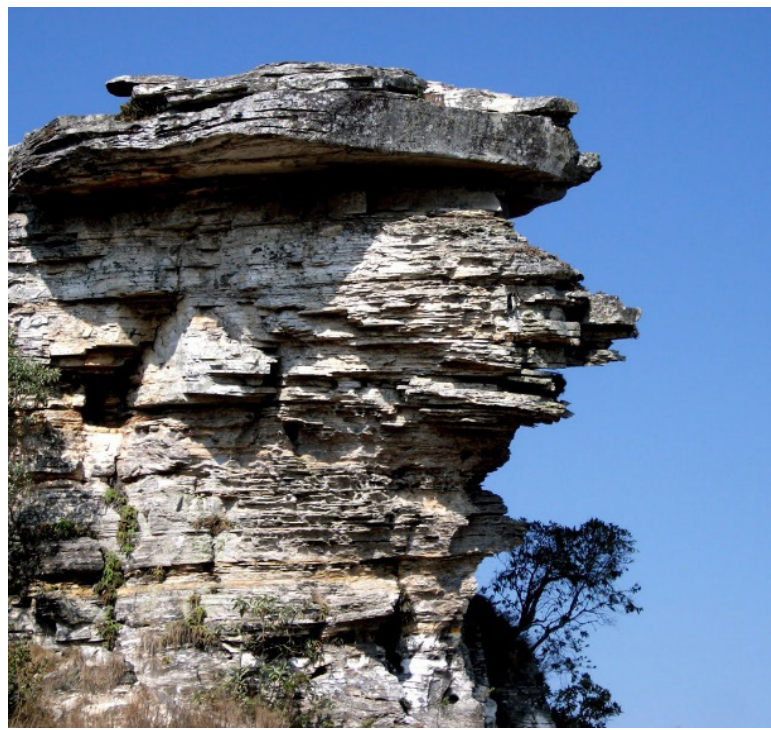

FIGURA 4 - Atrativo turístico Pedra da Bruxa.

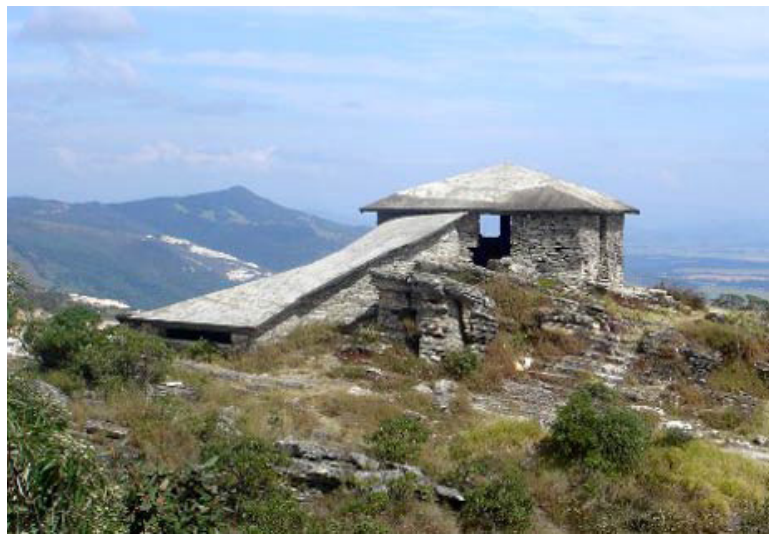

FIGURA 5 - Atrativo turístico Pirâmide.

As áreas de média aptidão para geoconservação estão próximas às minas inativas e aos afloramentos geológicos e se espalham pelas porções nordeste e noroeste de São Thomé das Letras, onde também ocorre uma densidade significativa de estradas e acessos. As faixas de menor aptidão estão localizadas nas porções sul e sudeste do município em estudo.

O cenário favorável à exploração mineral é apresentado na Figura 6. De acordo com a análise deste mapa, é possível observar que o município de São Thomé 
das Letras apresenta poucas áreas classificadas como de médio e alto potencial para mineração, de forma concentrada, para a realização da atividade minerária, conforme os critérios analisados.

Por meio do cruzamento dos dados de vias de acesso, processos minerários no Departamento Nacional de Pesquisa Mineral (DNPM), ocorrência de recurso mineral e minas ativas foi possível perceber que as áreas classificadas como de alta aptidão para a exploração mineral estão situadas onde ocorre o quartzito e, preferencialmente, próximas às estradas. A maior concentração de áreas com alto potencial está situada no sentido sudoeste-nordeste do município, ao longo da serra de São Thomé das Letras e do Cantagalo, correspondendo à área de ocorrência dessa rocha (Figuras 7, 8 e 9).

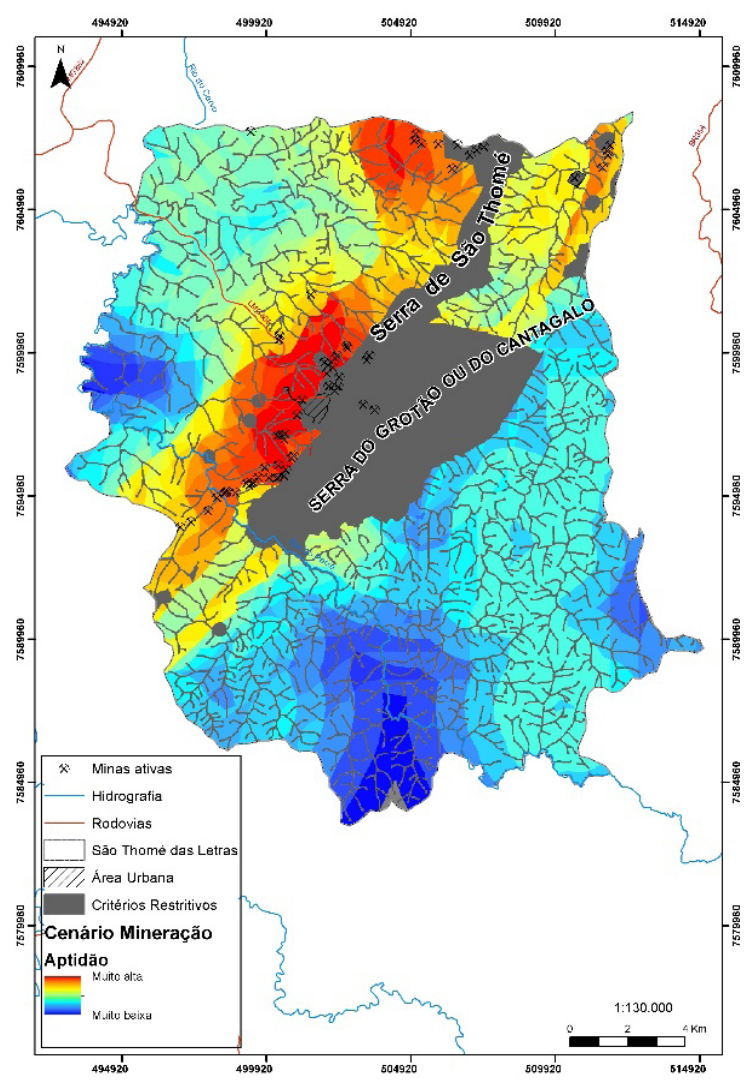

FIGURA 6 - Mapa de cenário favorável à exploração mineral.

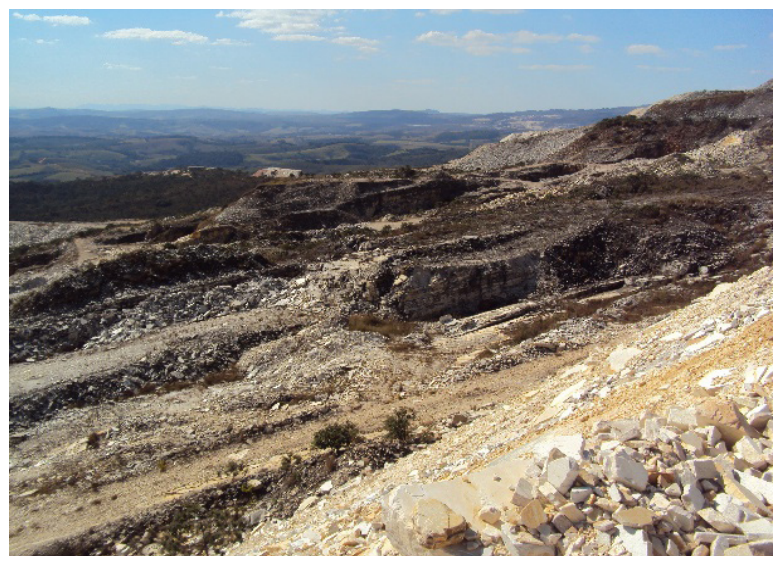

FIGURA 7 - Exemplo de área classificada como de alta aptidão para exploração mineral - Sobradinho.

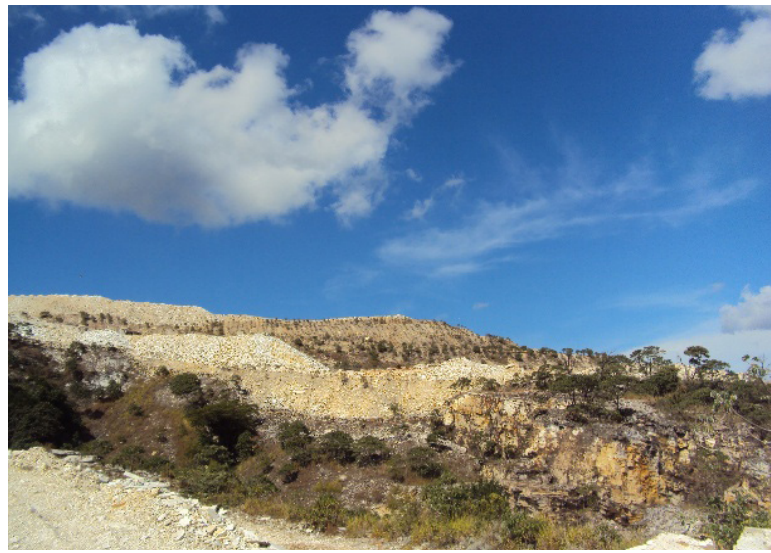

FIGURA 8 - Exemplo de área classificada como de alta aptidão para exploração mineral - Pico do Gavião.

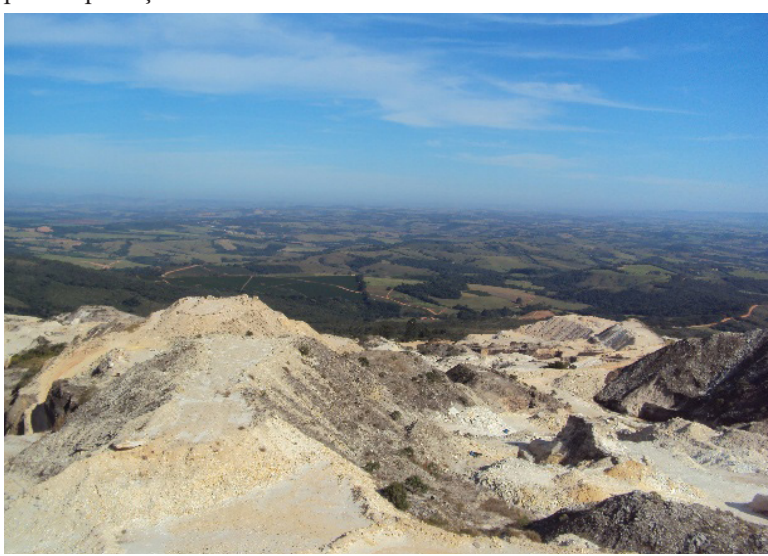

FIGURA 9 - Exemplo de área classificada como de alta aptidão para exploração mineral - Chapada. 


\subsection{Cenário integrado}

A partir dos mapas de cenários favoráveis à geoconservação e à exploração mineral, as possibilidades foram cotejadas de modo a promover a identificação das áreas onde a vocação para mineração ou para geoconservação são claramente definidas e onde há conflitos de interesse entre esses dois tipos de uso.

A análise com as possíveis combinações também foi realizada na estrutura de dados matricial, a matriz de combinação do cenário de geoconservação e de exploração mineral é mostrada na Tabela 3 e o mapa síntese desta combinação é apresentado na Figura 10.

Observam-se combinações onde existe clara definição do predomínio de aptidão para geoconservação ou do predomínio de áreas favoráveis para mineração. Em condições opostas, há áreas que são de alta a muito alta aptidão tanto para geoconservação como para mineração, o que gera os conflitos, ao passo que ocorrem também áreas de média a muito baixa aptidão para mineração e baixa a muito baixa aptidão para geoconservação, o que as define como sem conflitos.

A principal atividade a ser desenvolvida nessas áreas de conflitos deverá ser definida a partir das prioridades de interesses e no âmbito político, considerando argumentos e justificativas plausíveis para quaisquer das escolhas. Para essas áreas, seria importante uma seleção de locais propícios para a reconversão de territórios mineradores onde, inclusive, minas em atividade poderiam ser abertas para visitação pública considerando explicações ao público sobre o processo produtivo e a importância histórica da mineração da pedra São Tomé na região. Desta forma, poderia haver conciliação entre a exploração mineral e a geoconservação.

As áreas sem conflito são indicadas para os usos necessários da ocupação territorial que, se colocados em outras posições, gerariam conflitos, tais como aterros sanitários, parques industriais, usinas de reciclagem, entre outros. Nesta classificação estão terrenos que não são propícios nem para a geoconservação nem para a exploração mineral, mas que poderiam ser direcionados a outros usos.

As regiões onde há média aptidão para geoconservação e baixa aptidão para mineração são definidas como aptas às iniciativas de geoconservação, mas necessitam de investimentos para reconversão. Os investimentos para reconversão incluem tanto aqueles relacionados à reabilitação física das áreas como aqueles ligados ao seu uso para a geoconservação, incluindo, por exemplo, a instalação de centros de interpretação e educação ambiental. Como exemplo, podem-se citar as minas abandonadas do Pico do Gavião e do Poço Verde/Esmeraldas. Esta última já possui uso turístico, mas carece de medidas apropriadas para o desenvolvimento desta atividade.

TABELA 3 - Valores e classes da análise combinatória das matrizes.

\begin{tabular}{|c|cccccccc}
\hline Legenda & Aptidão & Mineração & Muito Alta & Alta & Média & Baixa & Muito Baixa \\
\hline Conflito & Geoconservação & Valores & 0 & 2 & 4 & 6 & 8 \\
\hline $\begin{array}{c}\text { Geocononservação } \\
\text { cuidadaca com }\end{array}$ & Muito Alta & 0 & 0 & 1 & 2 & 3 & 4 \\
\hline $\begin{array}{c}\text { Geoconservação com } \\
\text { investimento }\end{array}$ & Alta & 10 & 5 & 6 & 7 & 8 & 9 \\
\hline Mineração & Média & 20 & 10 & 11 & 12 & 13 & 14 \\
\hline Sem conflito & Baixa & 30 & 15 & 16 & 17 & 18 & 19 \\
\hline $\begin{array}{c}\text { Potencial de } \\
\text { Transformação }\end{array}$ & Muito Baixa & 40 & 20 & 21 & 22 & 23 & 24 \\
\hline
\end{tabular}




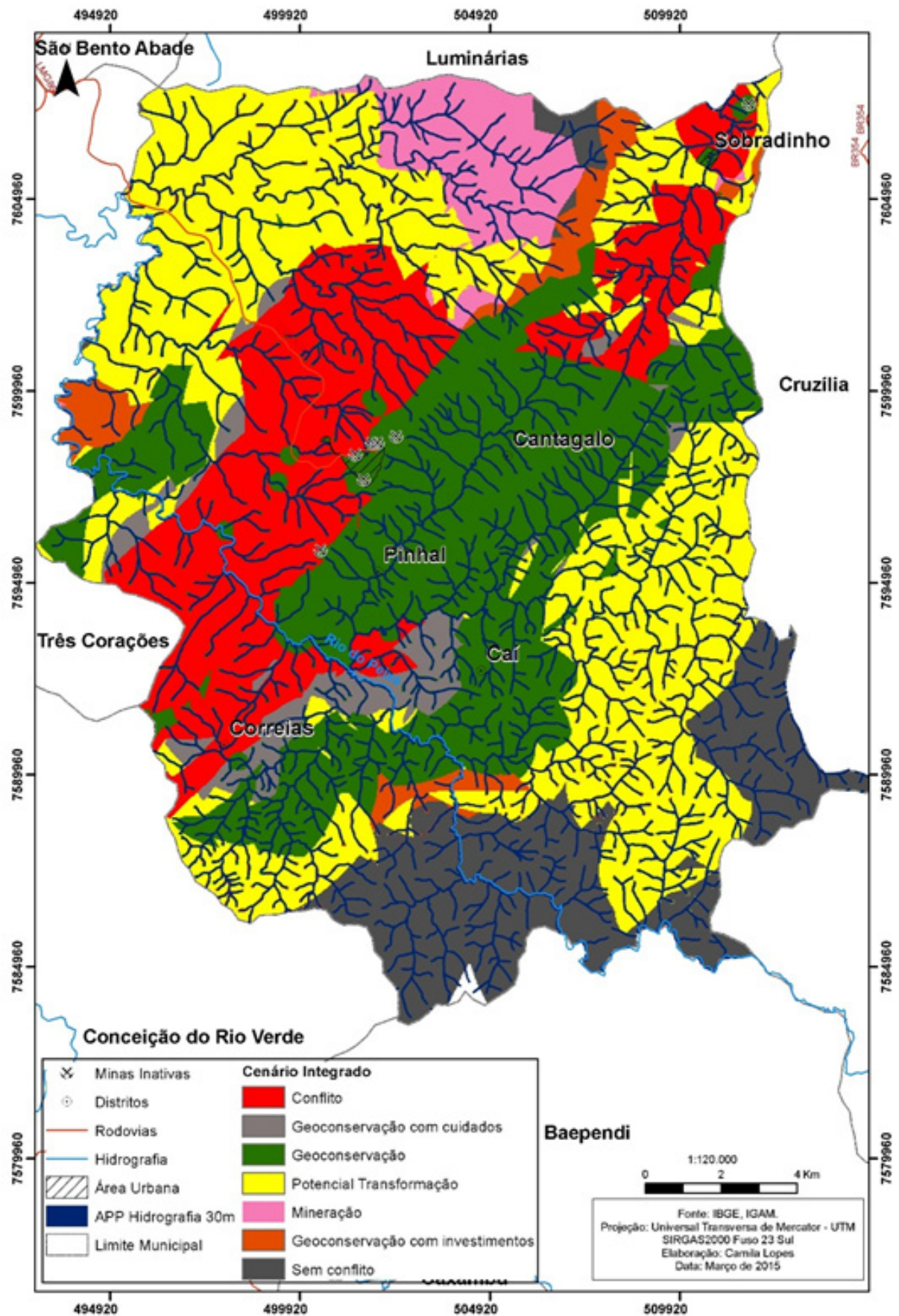

FIGURA 10 - Mapa síntese dos resultados: cenário integrado considerando a geoconservação e a exploração mineral. 
Áreas classificadas como de muito alta aptidão para geoconservação e média aptidão minerária são definidas como de interesse para geoconservação, mas são necessários cuidados de fiscalização e manutenção, já que existe uma pressão, considerando a média aptidão para mineração. Nestas áreas já existem locais utilizados pelo turismo e que poderiam ter produtos direcionados à valorização da geodiversidade, integrando uma proposta de reconversão. Como exemplo, podem-se citar o Vale das Borboletas, as corredeiras do Shangri-lá e a cachoeira da Lua. Estes locais já são utilizados do ponto de vista turístico, contudo, apresentam passivos ambientais decorrentes da atividade minerária, como assoreamento das drenagens.

Nas condições de combinações de médias aptidões, tanto para geoconservação quanto para mineração, encontram-se as regiões classificadas como de transição ou de potencial de transformação. Estas sãa extremamente relevantes para o planejamento territorial, uma vez que, ao serem propostas ações de transformação, não geram conflitos a princípio, além de potencializar a irradiação de resultados.

\section{Considerações finais}

A aplicação dos métodos de análise multicritério e a avaliação combinatória de matrizes de interesse para usos conflitantes, neste caso geoconservação e

\section{Referências}

Accioly, S. M. de L. Uso futuro de áreas mineradas e o meio urbano: o caso de Águas Claras. Belo Horizonte, Dissertação (Mestrado em Arquitetura) - UFMG, 2012.

Cañizares, M. C. Territorio y Patrimonio Minero-Industrial en Castilla-La Mancha. Cuenca: Ediciones de la Universidad de Castilla-La Mancha, 2005. Disponível em: <http://www. ub.edu/geocrit/b3w-623.htm>. Acesso em: maio 2015.

Cañizares, M. C. El atractivo turístico de una de las minas de mercurio más importantes del mundo: El Parque Minero de Almadén (Ciudad Real). Cuadernos de Turismo, 21, 9-31, 2008. Disponível em: <http://revistas.um.es/turismo/article/ view/24971>. Acesso em: maio 2015. mineração, se mostraram eficientes para o alcance dos objetivos propostos.

A despeito de um grande avanço, principalmente internacional, em medidas e ações direcionadas $\grave{a}$ reconversão de territórios mineradores, ainda há muito a ser feito no Brasil e em especial no Estado de Minas Gerais. A paralisação e o abandono de frentes de lavras, que atualmente ocorrem em várias áreas mineradoras, podem apresentar boas possibilidades para usos alternativos baseados na salvaguarda e na valorização da geodiversidade e do patrimônio mineiro, principalmente por meio da geoconservação e do turismo.

A pesquisa mostrou que o município de São Thomé das Letras pode conviver de forma não conflitante com a mineração e com a geoconservação e que esta última pode ser pensada como alternativa interessante para uso de áreas mineradas abandonadas ou paralisadas, valorizando a identidade cultural da região ligada à mineração.

Em São Thomé das Letras, a maior concentração de áreas potenciais para geoconservação coincide com as de mineração do município. Neste sentido, o resultado da análise pode subsidiar o ordenamento territorial e o planejamento municipal, favorecendo não só pesquisadores e turistas, mas a sociedade em geral. Este estudo pode auxiliar no planejamento em longo prazo da reconversão deste território mineiro de forma a utilizar ao mesmo tempo os recursos da geodiversidade e o patrimônio mineiro para o turismo.

Cañizares, M. C. Patrimonio, Parques Mineros y Turismo en España. Cuadernos de Turismo, 27, 133-153, $2011 \mathrm{a}$. Disponível em: $<$ http://revistas.um.es/turismo/article/viewFile/139801/125671>. Acesso em: maio 2015.

Cañizares, M. C. Protección y defensa del patrimonio minero en España. Scripta Nova. Revista Electrónica de Geografia y Ciencias Sociales, XV(361), 2011b. Disponível em: <http:// www.ub.edu/geocrit/sn/sn-361.htm>.

Carvalho, L. de S. C.; Pereira, A. F. Pedra São Thomé: valorização regional por meio da revitalização da paisagem e da identidade cultural. In: Anais do $9^{\circ}$ Congresso Brasileiro de 
Pesquisa e Desenvolvimento em Design. P\&D Design. São Paulo, 2010.

D'Auria, C. A. São Tomé das Letras na encruzilhada das fontes, dos tempos e dos saberes: um estudo sobre etnografia e historicidade com registros audiovisuais. Campinas, Dissertação (Mestrado em Artes) - UNICAMP, 2000.

Fernandes, T. M. G.; Godoy, A. M.; Fernandes, N. H. Caracterização petrográfica química e tecnológica dos quartzitos do centro produtor de São Tomé das Letras, sudoeste do Estado de Minas Gerais. In: Anais do III Simpósio de Rochas Ornamentais do Nordeste. Recife, 2002.

Gallego, E.; Garcia, A. El patrimonio geológico: bases para su valoración, protección, conservación y utilización. Madrid: Ministério de Obras Públicas, Transportes y Médio Ambiente de Espana (MOPTMA), 1996. p. 87-93. (Série Monografias)

Gray, M. Geodiversity: valuing and conserving abiotic nature. London: John Wiley and Sons, 2004.

Gesicki, A. L. D.; Santucci, R. M. Mineração e Geoconservação: o Sítio paleontológico de Santa Rosa de Viterbo, SP. Revista do Instituto Geológico, São Paulo, 32(1/2), 41-53, 2011. Disponível em: <http://www.ppegeo.igc.usp.br/pdf/rig/ v32n1-2/v32n1-2a04.pdf $>$.

Gutiérrez-Marco, J.C.; Sá, A. A.; Bellido, D. C.; Rábano, I.; Valério, M. Giant trilobites and trilobite clusters from the Ordovician of Portugal. Geology, 37(5), 443-446, 2009. doi: 10.1130/G25513A.1.

Hjort, J.; Luoto, M. Geodiversity of high-latitude landscapes in northern Finland. Elsevier Geomorphology, 115, 109-116, 2010. Disponível em: $<$ http://www.sciencedirect.com/science/ article/pii/S0169555X09004140>.

Liccardo, A.; Piekarz, G.; Salamuni, E. Geoturismo em Curitiba. Curitiba: Mineropar - Minerais do Paraná, 2008.

Lopes, R. M. F.; Freitas, V. L. O.; Maia-Barbosa, P. M. O que pensam as lideranças de São Tomé das Letras, MG, sobre as questões ambientais do município? Revista Monografias Ambientais, 11, 2326-2359, 2013.

Nieto, L. M. Patrimonio Geológico, Cultura y Turismo. Boletin del Instituto de Estudios Ginnenses, 182, 109-122, 2001.
Pellitero, R. O. Geomorfología, paleoambiente cuaternario y geodiversidad en el Macizo de Fuentes Carrionas-Montaña Palentina. Valladolid, Tese (Doutorado em Geografia) - Universidade de Valladolid, 2012.

Pereira, E. O.; Ruchkys, U. A.; Pellitero, R. O. Modelagem da geodiversidade na Área de Proteção Ambiental Sul da região metropolitana de Belo Horizonte - MG. Geonomos, 21(2), 97-101, 2013. Disponível em: <http://www.igc.ufmg.br/portaldeperiodicos/index.php/geonomos/article/viewFile/277/248>.

Rezende, M. A. P.; Dias, F. C.; Possato, F. M.; Aidar Filho, J. Patrimônio imaterial e sustentabilidade: o caso de São Thomé das Letras. In: Anais do III Encontro Latino-Americano sobre Edificações e Comunidades Sustentáveis, Recife, 2009.

Ruchkys, U. A. Sítios geológicos e propostas brasileiras de geoparques em geossistemas ferruginosos. In: Carmo, F. F.; Kamino, L. H. Y. (Org.). Geossistemas ferruginosos do Brasil: áreas prioritárias para conservação da diversidade geológica e biológica, patrimônio cultural e serviços ambientais. Belo Horizonte: 3i Editora, 2015. p. 169-194.

Ruchkys, U. A.; Machado, M. M. M. Patrimônio geológico e mineiro do Quadrilátero Ferrífero, Minas Gerais - caracterização e iniciativas de uso para educação e geoturismo. Boletim Paranaense de Geociências, 70, 120-133, 2013. Disponível em: <http://ojs.c3sl.ufpr.br/ojs/index.php/geociencias/article/ view/31541>.

Saiz de Omeñaca, J.; Saiz de Omeñaca, J. A. La "Reconversion Ambiental" de le Minería a Cielo Abierto en España. Informes de la Construcción, 47, 441-442, 1996.

Santos, M. G. V. Avaliação da reabilitação in loco com espécies nativas, de pilha de estéril gerada por mineração de quartzito, no municipio de São Thomé das Letras, Minas Gerais. Belo Horizonte, Dissertação (Mestrado em Biologia) - UFMG, 2005.

Serrano, E.; Ruiz-Flaño, E. C. Geodiversidad: concepto, evaluación y aplicación terrotorial. El caso de Tiermes Caracena (Soria). Boletín de la A.G.E., 45, 79-98, 2007.

Travassos, L. E. P.; Varela, I. D.; Guimarães, R. L. Áreas cársticas, cavernas e a Estrada Real. Pesquisas em Turismo e Paisagens Cársticas, 1(2), 107-120, 2008. Disponível em: $<$ http://www.sbe.com.br/ptpc/ptpc_v1_n2_107-120.pdf $>$. 